\title{
Peningkatan Pelayanan BMT Bina Umat Mandiri (BUM) Kota Tegal Melalui Pelatihan Training of Trainer
}

\section{Catur Wahyudi*1, Setyowati Subroto², Mohammad Arridho Nur Amin³, Ira Maya Hapsari4, Mei Rani Amalia5, Agnes Dwita Susilawati $^{6}$}

\author{
1,2,3,4,5,6Fakultas Ekonomi dan Bisnis, Universitas Pancasakti Tegal, Indonesia \\ *e-mail: mohammad.arridho@gmail.com ${ }^{3}$
}

\begin{abstract}
Abstrak
BMT Bina Umat Mandiri cabang tegal memiliki kekurangan dalam pelayanan kepada nasabah, serta selama ini tidak menggunakan teknik cross selling dalam pelayanannya, hasil observasi tim pengabdian menemukan tidak adanya pelatihan mendalam mengenai service excellent dan teknik cross selling yang diterapkan oleh customer service dan marketing BMT BUM Kota Tegal, hal tersebut membuat pertumbuhan dana anggota di BMT BUM Kota Tegal tidak maksimal. Melihat kondisi ini tim pengabdian UPS Tegal melakukan Training of Trainer (ToT) ini untuk memberikan pengetahuan serta praktek langsung bagi kepala bagian maupun kepala cabang mengenai pelayanan serta kemampuan dalam melakukan service excellent dan teknik cross selling terhadap produk yang BMT BUM Kota Tegal jual. Kegiatan sosialisasi dan pelatihan ToT dilakukan dengan metode penyuluhan dan demonstrasi kepada kepala cabang dan kepala bagian di setiap kantor kas di Kota Tegal yang nantinya kepala cabang serta kepala bagian tersebut memberikan pelatihan kepada staff frontliner masing-masing kantor kas, Kegiatan ini dihadiri narasumber berasal dari dosen Fakultas Ekonomi dan Bisnis Universitas Pancasakti Tegal. Manfaat yang diperoleh peserta dari kegiatan PKM ini antara lain agar dapat lebih baik lagi dalam pelayanan kepada anggota maupun calon anggota BMT BUM, serta mengoptimalkan pertumbuhan yang didapatkan melalui strategi cross selling yang dilakukan oleh seluruh karyawan BMT BUM Kota Tegal khususnya pada Customer Service pada setiap cabang BMT BUM Kota Tegal.
\end{abstract}

Kata kunci: BMT BUM, Cross Selling, Pelayanan, Trainig of Trainer

\begin{abstract}
BMT Bina Umat Mandiri Tegal branch has shortcomings in service to customers, and so far it has not used cross selling techniques in its services, the observation results of the service team found that there was no in-depth training on service excellence and cross selling techniques applied by customer service and marketing BMT BUM City Tegal, this makes the growth of member funds in BMT BUM Tegal City is not optimal. Seeing this condition, the UPS Tegal community service team conducted this Training of Trainer (ToT) to provide knowledge and direct practice for section heads and branch heads regarding services and the ability to perform excellent service and cross selling techniques for products sold by BMT BUM Tegal city. ToT socialization and training activities were carried out using counseling and demonstration methods to branch heads and section heads at each cash office in Tegal City, which later branch heads and division heads provided training to frontliner staff of each cash office. This activity was attended by resource persons from lecturers, Faculty of Economics and Business, Universitas Pancasakti Tegal. The benefits obtained by participants from this community service activity include being able to better serve members and prospective members of BMT BUM, as well as optimizing the growth obtained through a cross selling strategy carried out by all employees of BMT BUM Tegal City, especially in Customer Service at each branch of BMT BUM Tegal City.
\end{abstract}

Keywords: BMT BUM, Cross Selling, Services, Training of Trainer

\section{PENDAHULUAN}

Perusahaan yang menjual suatu produk, baik produk berwujud (tangible) seperti makanan, minuman, aksesoris kendaraan ataupun produk yang tidak berwujud (intangible) seperti deposito, pinjaman, ataupun tabungan perlu melakukan strategi cross selling yaitu dengan menjual produk lain ke anggota/nasabah yang sama, hal tersebut dilakukan agar anggota/nasabah agar tetap setia dan atau tidak beralih ke produk, merek maupun perusahaan jasa keuangan lain (Awalin, 2012). Knott, Hayes, \& Neslin, (2002) Strategi cross selling disini 
dilakukan oleh seorang customer service. Seorang customer service memegang peranan sangat penting disamping memberikan pelayanan juga sebagai pembina hubungan dengan masyarakat atau public relation. Customer service dalam melayani para nasabah selalu berusaha menarik dengan cara merayu para calon nasabah agar menjadi anggota/nasabah koperasi yang bersangkutan dengan berbagai cara. Customer service juga harus dapat menjaga nasabah lama agar tetap menjadi anggota/nasabah. Oleh karena itu tugas-tugas yang diemban oleh para customer service merupakan tulang punggung kegiatan operasional dalam perusahaan jasa keuangan (Pamungkas et al., n.d.).

Service excellent/pelayanan prima merupakan pelayanan yang sangat baik atau pelayanan yang terbaik. Disebut sangat baik atau terbaik, karena sesuai dengan standar pelayanan yang berlaku atau dimiliki oleh perusahaan yang memberikan pelayanan harus memiliki standar pelayanan yang dapat menjadi ukuran dalam memuaskan anggota/nasabah (Arif, 2012). Service Excellent sangat diperlukan untuk memberikan rasa puas terhadap nasabah, sehingga pelanggan merasa dirinya dipentingkan atau diperhatikan sebagaimana mestinya (Barata, 2003). Jika anggota/nasabah merasa puas maka mereka akan setia dan terus menggunakan produk jasa yang digunakan. Nasabah akan membicarakan hal baik tentang pelayanan BMT BUM Kota Tegal yang diperolehnya kepada orang lain, tidak terlalu memperhatikan pesaing dan tidak terlalu sensitive terhadap produknya. service excellent terhadap nasabah sangat penting karena merupakan strategi memenangkan pesaing (Semil, 2018).

Silvanita, (2021) BMT BUM Kota Tegal merupakan salah satu Koperasi terbesar di Kota Tegal, dengan berstatus perusahaan jasa keuangan BMT BUM Kota Tegal ingin memiliki memiliki SDM yang unggul serta dapat memberikan excellent service kepada seluruh anggota/nasabahnya, beberapa kali tim pengabdian mengunjungi kantor kan dan kantor cabang BMT BUM namun pelayanan yang diberikan tidak memuaskan dan tidak terstandarisasi, dan juga baik teller maupun customer service tidak ada yang melakukan cross selling kepada anggota maupun calon anggota BMT BUM. Melalui hasil observasi yang dilakukan tim pengabdian diketahui beberapa permasalahan yang teridentifikasi di lokasi pengabdian sehingga dirasa penting untuk segera dilakukan pelatihan, antara lain: tidak dilakukannya dan ditegaskan melakukan service excellent bagi staff frontliner, tidak melakukan cross selling terhadap calon anggota dan anggota, tidak adanya SOP yang mendasari, tidak ada standarisasi berbusana staff frontliner. Masih rendahnya pengetahuan staff BMT BUM Kota Tegal tentang Service Excellent dan Cross Selling membuat anggota menjadi kurang loyal terhadap BMT BUM sehingga hanya menggunakan produk yang diperlukan saja, hal tersebut di perparah dengan kurangnya kualitas pelayanan yang diberikan sehingga membuat anggota BMT BUM kurang memilki rasa kekeluargaan. Dengan service excellent maka orang akan merasa puas terhadap pelayanan yang di terapkan oleh suatu lembaga sehingga akan menunbuhkan loyalitas (Nurlia, 2018)

Melihat kondisi ini tim pengabdian berkoordinasi dengan pejabat BMT BUM Kota Tegal menyusun jadwal pelaksanaan kegiatan Sosialisasi dan Pelatihan Training of Trainer Service Excellent dan Cross Selling. Kegiatan pengabdian pada masyarakat bagi dosen-dosen di Fakultas Ekonomi dan Bisnis Universitas Pancasakti Tegal yang saat ini diperlukan oleh staff BMT BUM Kota Tegal. Dari masalah-masalah tersebut dapat dirumuskan masalah sebagai berikut:

a. Bagaimana meningkatkan pengetahuan dan kemampuan staff BMT BUM Kota Tegal tentang Excellent Service.

b. Bagaimana meningkatkan pengetahuan dan kemampuan staff BMT BUM Kota Tegal dalam melakukan Cross Selling.

Oleh karena itu dipandang perlu bagi dosen-dosen Fakultas Ekonomi dan Bisnis melakukan sosialisasi dan pelatihan bagi staff BMT BUM Kota Tegal tentang cara melakukan Service Excellent dan Cross Selling terhadap calon anggota dan anggota dengan baik dan benar, sehingga dapat meningkatkan pertumbuhan dana anggota yang di terima oleh BMT BUM Kota Tegal. 


\section{METODE}

\subsection{Metode Kegiatan}

Metode kegiatan ini berupa pelatihan Traning For Trainer manajemen pelayanan kepada karyawan beserta KSPPS BMT BUM Kota Tegal. Karyawan diberi 4 pemahaman untuk menerapkan konsep manajemen pelayanan terhadap nasabah dalam rangka meningkatkan daya saing lemabag keuangan syariah. Berikut ini adalah tahapan pelatihan yang dilakukan:

1. Tahap Persiapan

Tahap persiapan yang dilakukan meliputi:

a. Survey

b. Pemantapan dan penentuan lokasi dan sasaran

c. Penyusunan bahan/materi pelatihan, yang meliputi makalah dan modul untuk kegiatan pelatihan

2. Tahap pelaksanaan pelatihan

Tahap pelaksanaan pelatihan dilakukan persiapan. Dalam tahap ini dilakukan pertama, penjelasan tentang konsep manajemen sdm dan pelayanan, sesi pelatihan ini menitikberatkan pada pemberian penjelasan pemahaman manajemen pelayanan yang tepat sesuai era globalisasi; kedua, sesi penjelasan tentang bagaiman berkomunikasi yang efektif.

3. Metode Pelatihan

Untuk melaksanakan kegiatan tersebut digunakan beberapa metode pelatihan, yaitu:

a. Metode ceramah dipilih untuk memberikan penjelasan tentang konsep manajemen usaha dan fungsinya.

b. Metode tanya jawab penting bagi para peserta pengabdian, di saat menerima penjelasan tentang teori.

\subsection{Metode Simulasi}

Metode simulasi ini sangat penting diberikan kepada para peserta untuk memberikan kesempatan mensimulasi masalah terkait manajemen pelayanan. Permasalahan yang diangkat dalam kegiatan pengabdian pada masyarakat di BMT BUM Kota Tegal adalah memberikan pelatihan/training manajemen pelayanan kepada Direksi, manajer divisi, kepala cabang BMT BUM.

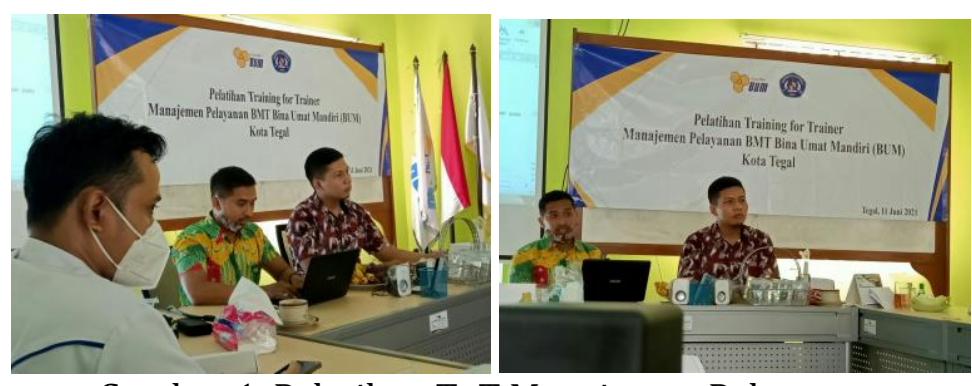

Gambar 1. Pelatihan ToT Manajemen Pelayanan.

Pemahaman manajemen pelayanan terhadap karyawan yang tepat bermanfaat bagi BMT BUM dalam meningkatkan daya saing. Oleh karena itu, diusulkan kerangka pemecahan masalah secara operasional sebagai berikut

Kerangka pemecahan masalah dengan menerapkan langkah kerja dalam pengabdian masyarakat sebagai berikut:

1. Menetapkan jumlah peserta pelatihan yaitu mengambil seluruh direksi, manajer divisi, dan kepala Cabang.

2. Semua peserta dikumpulkan di suatu tempat/ruangan yang memadai untuk penyelenggaraan pelatihan, yang akan dilaksanakan pengenalan dan pemahaman konsep (tatap muka) minimal selama \pm 8 jam (1 hari).

3. Memberikan pelatihan melalui materi dan praktik yang meliputi: 
a. Materi 1: pemahaman tentang penilaian kepuasan pelanggan atau konsumen.

b. Materi 2: pemahaman tentang membangun konsep Cross Selling.

c. Praktik 1: kegiatan Roleplay pelayanan Customer Service dan Teller.

d. Praktik 4: kegiatan Roleplay untuk Cross Selling.

\section{HASIL DAN PEMBAHASAN}

Kegiatan Pengabdian masyarakat pelatihan Training for Trainer manajemen pelayanan bagi direksi dan manajer serta kapala cabang KSPPS BMT BUM Kota Tegal dilaksanakan dengan metode tatap muka dan diskusi berjalan lancar dan baik. Pelaksanaan kegiatan dilaksanakan tanggal 11 Juni 2021. Pertemuan tatap muka diberikan dengan cara ceramah penilaian dan model pelayanan prima dan parktik langsung oleh peserta. Kegiatan dilanjutkan dengan tanya jawab dari peserta dan tim pelaksana Pengabdian masyarakat. Pelaksanaan kegiatan dilakukan di gedung BMT BUM Kota Tegal. Pelaksanaan kegiatan ini dilakukan oleh sembilan orang tim pengabdi dengan pokok bahasan yang disampaikan mengenai pemahaman konsep penilaian pelayanan karyawan, kegiatan cross selling dan parktik langsung pelayanan prima yang efektif untuk karyawan.

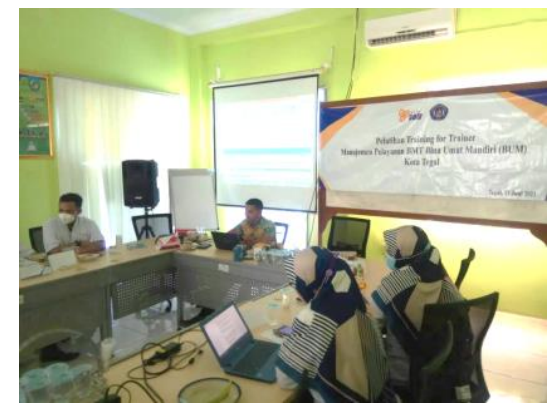

Gambar 2. Peserta Pelatihan ToT antusias memberikan pertanyaan

Peserta mengikuti kegiatan dengan antusias hal ini ditunjukkan dengan pertanyaanpertanyaan dan tanggapan mengenai materi yang diberikan. Pertanyaan-pertanyaan berkaitan dengan materi dari pengabdi dan permasalahan yang dihadapi peserta saat berada di lapangan. Secara umum pertanyaan peserta sebagai berikut:

a. Membuat penilaian terhadap Customer Service agar optimal.

b. Penilaian capaian kepuasan pelanggan/anggota koperasi.

c. Konsep Cross Selling yang menarik.

d. Menghadapi anggota koperasi dengan menggunakan bahasa yang menarik.

Training for Trainer manajemen pelayanan bagi pimpinan KSPPS BMT BUM Kota Tegal dalam program pengabdian masyarakat yang sudah terlaksana ini diharapkan dapat memberikan pemahaman dan juga kemampuan karyawan KSPPS BMT BUM Kota Tegal yang akan berdampak pada peningkatan kompetensi pengelolaan pelayanan dalam jasa keuangan syariah. Manfaat kegiatan secara langsung bagi karyawan KSPPS BMT BUM Kota Tegal dalam menghadapi permasalahan-permasalahan manajemen.

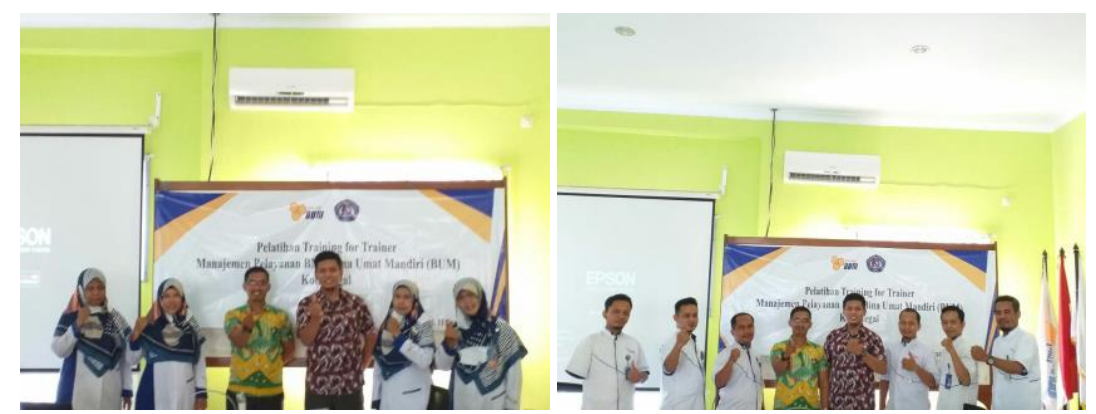

Gambar 3. Penyelesaian SOP BMT BUM Kota Tegal 


\section{KESIMPULAN}

Kesimpulan mengenai kegiatan pengabdian masuarakat di BMT BUM Kota Tegal sebagai berikut: Pelatihan ToT manajemen pelayanan bagi BMT BUM Kota Tegal berfokus terhadap excellent service dan pelaksanaan cross selling setidaknya dari yang tidak tahu menjadi tahu serta berhasil dalam praktek langsung dalam pelaksanaan pelayanan dan cross selling. Peningkatan pemahaman bagi peserta pelatihan dilakukan dengan metode ceramah, demonstrasi serta praktek langsung yang dilakukan oleh peserta pelatihan, dan juga dilakukan tanya jawab. Kegiatan pengabdian ini diharapkan ke depannya dapat dilakukan kembali untuk dilakukan evaluasi serta dilakukan pendampingan lanjutan sehingga dapat lebih maksimal dalam pelayanan dan pelaksanaan cross selling.

\section{DAFTAR PUSTAKA}

Al Arif, N. R. (2012) Dasar-Dasar Pemasaran Bank Syariah. Bandung: Alfabeta.

Awalin, F. R. (2017). Strategi Cross Selling Dalam Rangka Penghimpunan Dana Pihak Ketiga (Studi Pada Customer Service Di BTN Kantor Cabang Syari'ah Tegal) Cross Selling Strategy In The Framework Of Third Party Fund Purchasing (Study On Customer Service At BTN Kantor Cabang Syari'ah Tegal) (Doctoral dissertation, IAIN Purwokerto).

Barata, A. A. (2003). Dasar-dasar pelayanan prima. Elex Media Komputindo.

Knott, A., Hayes, A., \& Neslin, S. A. (2002). Next-product-to-buy models for cross-selling applications. Journal of interactive Marketing, 16(3), 59-75.

Nurlia. (2018). STRATEGI PELAYANAN DENGAN KONSEP SERVICE EXCELLENT Nurlia. Meraja Journal, 1(2), 17-30.

Pamungkas, A., Murdiati, S., \& Tegal, U. P. (n.d.). $H$ ubungan $K$ esadaran , $P$ engetahuan dan $P$ emahaman, dan Kualitas Pelayanan $D$ engan $K$ emauan $M$ embayar $P$ ajak $B$ umi dan $B$ angunan di Desa D ukuhturi K ecamatan D ukuhturi Kabupaten T egal.

Semil, N. (2018). Pelayanan prima instansi pemerintah: kajian kritis pada sistem pelayanan publik di Indonesia. Prenada Media.

Silvanita, F. F. (2021). ANALISIS PENGARUH KUALITAS PELAYANAN DAN PROMOSI TERHADAP KEPUTUSAN NASABAH MENABUNG PADA BMT BUM CABANG ADIWERNA (Doctoral dissertation, Politeknik Harapan Bersama Tegal). 


\section{Halaman Ini Dikosongkan}

